\title{
Nitrazepam (Mogadon) in blood serum and urine and librium in urine
}

\author{
S. L. TOMPSETT \\ From the Department of Clinical Chemistry (University of Edinburgh), \\ Royal Infirmary, Edinburgh
}

SYNOPSIS A method is described for the determination of nitrazepam and its reduced product in blood serum and urine. The metabolite, the reduced product, is the principal substance to be encountered in these fluids. A method is also described for the determination of librium (and thew lactam) in urine.

Nitrazepam (1,2 dihydro-7-nitro-2-oxo-5-phenyl3H-1,4-benzodiazepine) is one of the recently introduced sleep-inducing drugs and it can be purchased without prescription. Cases of overdosage have been reported from the continent of Europe (Rieder, 1965), and such cases have also been seen at the Poisoning Treatment Centre at Edinburgh Royal Infirmary.

Rieder (1965) has described a method for the determination of nitrazepam in blood serum, and is based on the technique of Bratton and Marshall (1939). It appears that nitrazepam circulates and is excreted (1) unchanged, (2) in a reduced form, the nitro group having been reduced to an amino group, and (3) as an acetyl compound of (2). The method of Rieder appears to be inadequate for the assessment of (3), since relatively strong acid treatment is required for the removal of the acetyl group and possibly results in some decomposition of the substance to form a benzophenone. Our own investigations show that the major part of the ingested nitrazepam circulates and is excreted as compounds (2) and (3). Another difficulty associated with assessing overdosage is that the effective dose is low, ie, of the order of $5 \mathrm{mg}$.

An improved technique is described in this paper. As a preliminary, nitrazepam and its derivatives are converted to their respective benzophenones allowing more exact quantitative data to be obtained and also complete hydrolysis of any acetyl compounds present. Formation of benzophenone under the conditions described below is not peculiar to nitrazepam but occurs also with librium, librium lac-

Received for publication 7 September 1967. tam, and valium (Randall, 1961); Bäumler and Ripe penstein, 1961 ; de Silva, Koechlin, and Bader, 1966) The technique of Bratton and Marshall is moss suitable for the final assessment. Benzophenoneso reacting to this technique are also produced frong librium and its lactam, although the benzophenone derived from valium itself does not react bu valium is metabolized, at least in part, to libriun: lactam. Solvent extraction, together with $\mathrm{pH}$ controf and choice of solvent, have been used to achievet some degree of specificity.

The question naturally arises as to which is the most suitable material, blood or urine, to use fơ examinations. Gastric aspirates are usually available but frequently do not contain any identifiable material. Such figures, even if available, are not ready index of the extent of the ingestion. Undef the present circumstances, urine appears to give results which can be most easily interpreted. Difficulties have been experienced in using bloo\& serum.

CHEMICAL AND PHYSICAL PROPERTIES OF
NITRAZEPAM

The chemical and physical properties of nitrazepam havio been examined and extended to include related substances such as librium (and the lactam) and valium (sometimes referred to as diazepam).

PREPARATION OF REDUCED NITRAZEPAM Nitrazepam was reduced by the method of Rieder (1965). To $1 \mathrm{mg}$ of nitrazepam contained in $10 \mathrm{ml}$ of water was adde 8 $60 \mathrm{mg}$ of magnesium oxide. The mixture, $\mathrm{pH}$ about $1 \mathrm{~S}_{3}$ was shaken for $30 \mathrm{sec}, 0.5 \mathrm{~g}$ of sodium dithionite waig added, the mixture shaken for 10 minutes, and the placed in a water bath at $50^{\circ} \mathrm{C}$ for one hour. 
Reduction may also be achieved with zinc dust in the presence of hydrochloric acid but zinc causes difficulties when solvent procedures are applied.

PREPARATION OF THE BENZOPHENONES The method of de Silva et al. (1966) was used. One hundred $\mu \mathrm{g}$ of the substance in $2 \mathrm{ml}$ of $5 \mathrm{~N}$ hydrochloric acid, contained in a glass tube fitted with a glass stopper, was placed in a boiling water bath for one hour. (The glass stopper is not placed in position until the contents of the tube have attained the temperature of the water bath.) The contents of the tube are diluted to $10 \mathrm{ml}$ with water, after which any extraction with an organic solvent may be applied.

ULTRAVIOLET SPECTROPHOTOMETRY Absorbance curves, recorded between 200 and $400 \mathrm{~m} \mu$, should be available (Unicam recording spectrophotometer SP 800), made in acid ( $N$ hydrochloric acid) and alkaline ( $N$ sodium hydroxide) solutions. Curves for nitrazepam, reduced nitrazepam, valium, librium, and the lactam and the benzophenones derived from nitrazepam, reduced nitrazepam, and librium are shown in the figure. Librium lactam gives the same benzophenone as librium. Each is a typical absorbance curve and reasonably sensitive: 10 or $20 \mu \mathrm{g} / \mathrm{ml}$ will suffice.

This technique is not readily applicable to determinations in blood serum and urine owing to insensitivity on account of the low concentrations usually encountered and the effect of interfering substances.

The ultraviolet technique is applicable when identification of tablets or gastric residues is required, provided that a certain amount of purification has been carried out. When large quantities are encountered in urine, it may be applied to extracts provided that purification has been adequate.

REACTION IN THE BRATTON AND MARSHALL TECHNIQUE Reduced nitrazepam and the benzophenones derived from nitrazepam, reduced nitrazepam and librium (and the lactam) react. Nitrazepam and librium do not react. Neither valium nor the benzophenone derived from this substance react.

VOLATILITY A quantity of the substance $(100 \mu \mathrm{g})$ contained in $50 \mathrm{ml}$ water and after the addition of $1 \mathrm{~g}$ sodium hydrogen carbonate was distilled in an all-glass distillation apparatus until $30 \mathrm{ml}$ of distillate had been collected. The benzophenone of librium was recovered completely in the distillate. Nitrazepam, reduced nitrazepam, librium (and the lactam), and the benzophenones derived from nitrazepam and reduced nitrazepam could not be recovered under such circumstances. The Bratton and Marshall technique was used to evaluate the results. To prevent loss when solutions of the benzophenone in an organic solvent, eg, n-heptane, are evaporated to dryness, a few drops of $10 \mathrm{~N}$ hydrochloric acid are included in the mixture.

EXTRACTION WITH ORGANIC SOLVENTS A standard procedure is used in this laboratory. To $10 \mathrm{ml}$ of solution are added (a) $1 \mathrm{ml} 10 \mathrm{~N}$ hydrochloric acid (acid reaction); (b) $1 \mathrm{ml} 10 \mathrm{~N}$ hydrochloric acid followed by an excess of solid sodium hydrogen carbonate (neutral reaction); and (c) $1 \mathrm{ml} 10 \mathrm{~N}$ sodium hydroxide (alkaline reaction) followed by $40 \mathrm{ml}$ of the solvent under examination. The mixture is shaken vigorously for two minutes, and $30 \mathrm{ml}$ of the solvent separated for examination.

Using this procedure, the benzophenones obtained from librium, unchanged and reduced nitrazepam were examined. The benzophenones of librium and unchanged nitrazepam were extracted by both $\mathrm{n}$-heptane and chloroform under conditions $(a),(b)$, and $(c)$. Both are efficient solvents but $n$-heptane is more selective. The benzophenone obtained from reduced nitrazepam was extracted by both solvents under conditions $(b)$ and (c) but extraction with chloroform was more efficient.

CATION EXCHANGE RESINS The system of Tompsett (1960) was used. The benzophenones obtained from librium and unchanged and reduced nitrazepam were retained by the column and required hydrochloric acid of normality at least 8 to effect elution.

THIN-LAYER CHROMATOGRAPHY The Eastman chromagram chamber plate set and Eastman chromagram sheets (silica gel $20 \times 20 \mathrm{~cm}$ ) were used with the solvent system n-heptane/chloroform/ethanol (20/20/1), and the following $\mathbf{R}_{\mathbf{f}}$ values were obtained: benzophenone derived from librium, 0.75 , nitrazepam, 0.54 , reduced nitrazepam, $0 \cdot 44$. Ultraviolet light will show black spots (254 and $365 \mathrm{~m} \mu$ ). After extraction from the chromatogram with $\mathrm{N}$ hydrochloric acid, the Bratton and Marshall technique may be applied and the ultraviolet recording spectrophotometer used.

INFRARED SPECTROPHOTOMETRY Excellent infrared spectra of the benzophenones of librium and nitrazepam have been obtained using the Unicam infrared spectrometer SP 200 fitted with Wilk's model 9 internal reflector plate $(50 \times 2 ; 2 \mathrm{~mm}$; material $\mathrm{AgCl})$. The spectra so obtained are quite distinctive. Suitable spectra may be obtained when the quantity of material available is $1 \mathrm{mg}$ or even less. This procedure is still in the experimental stage but is being used much more widely.

\section{DETERMINATION OF NITRAZEPAM (UNCHANGED AND REDUCED) IN URINE}

REAGENTS N-heptane (Analar), chloroform (Analar), solid sodium hydrogen carbonate, $0 \cdot 1 \% \mathrm{w} / \mathrm{v}$ sodium nitrate, $0.5 \% \mathrm{w} / \mathrm{v}$ ammonium sulphamate, and $0.1 \%$ w/v N-naphthyl ethylene diamine dihydrochloride.

STANDARD SOLUTIONS These were prepared from substances supplied by the manufacturers.

STOCK STANDARD SOLUTIONS Nitrazepam is prepared in $50 \%$ ethanol $(\mathrm{v} / \mathrm{v})$ and contains $1 \mathrm{mg} / \mathrm{ml}$. Librium is in the form of the hydrochloride in $\mathbf{N}$ hydrochloric acid and contains $1 \mathrm{mg} / \mathrm{ml}$.

PREPARATION OF NITRAZEPAM AND LIBRIUM STANDARDS FOR USE Working standards containing benzophenone equivalent to 25,50 , and $100 \mu \mathrm{g}$ of these substances in 

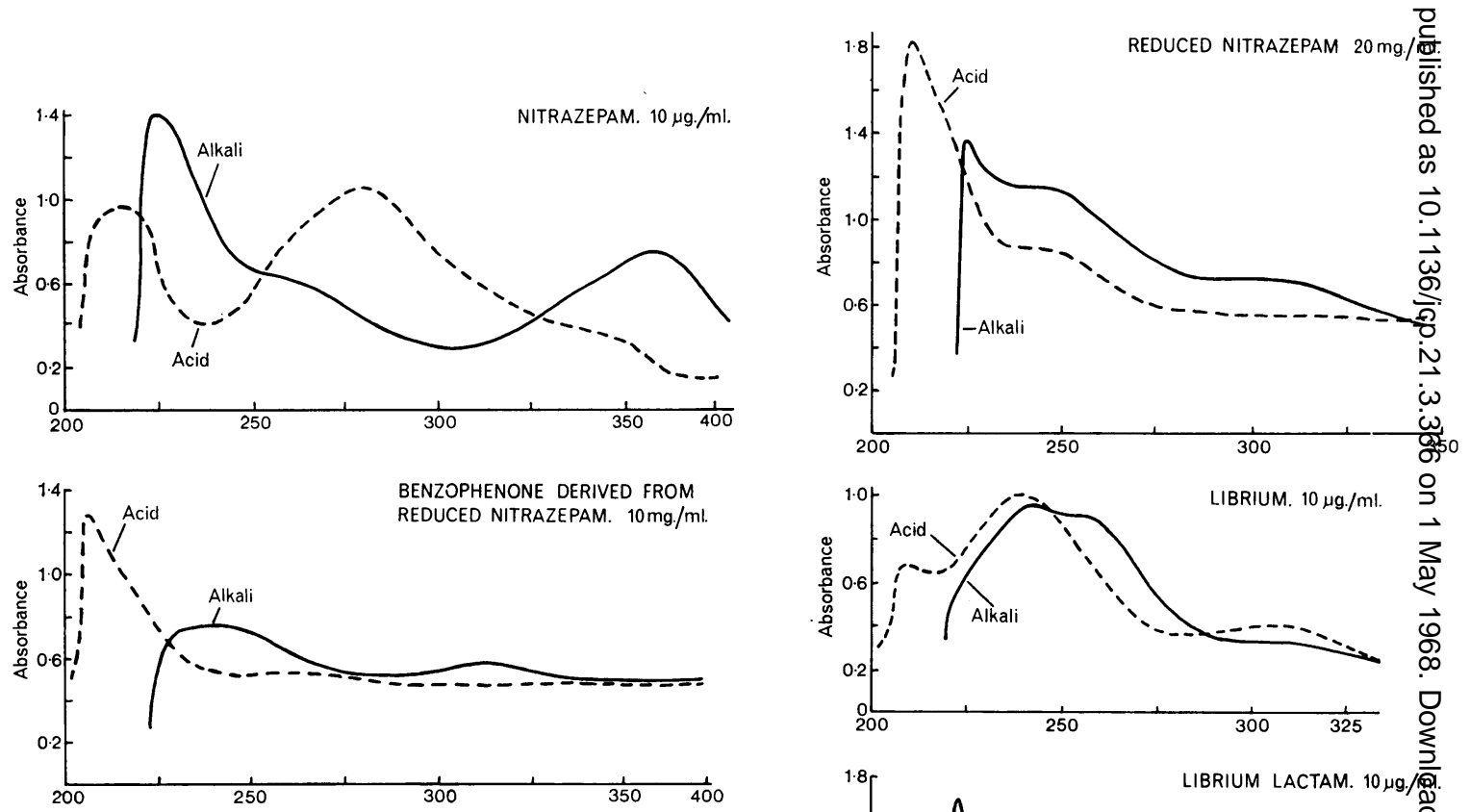

온
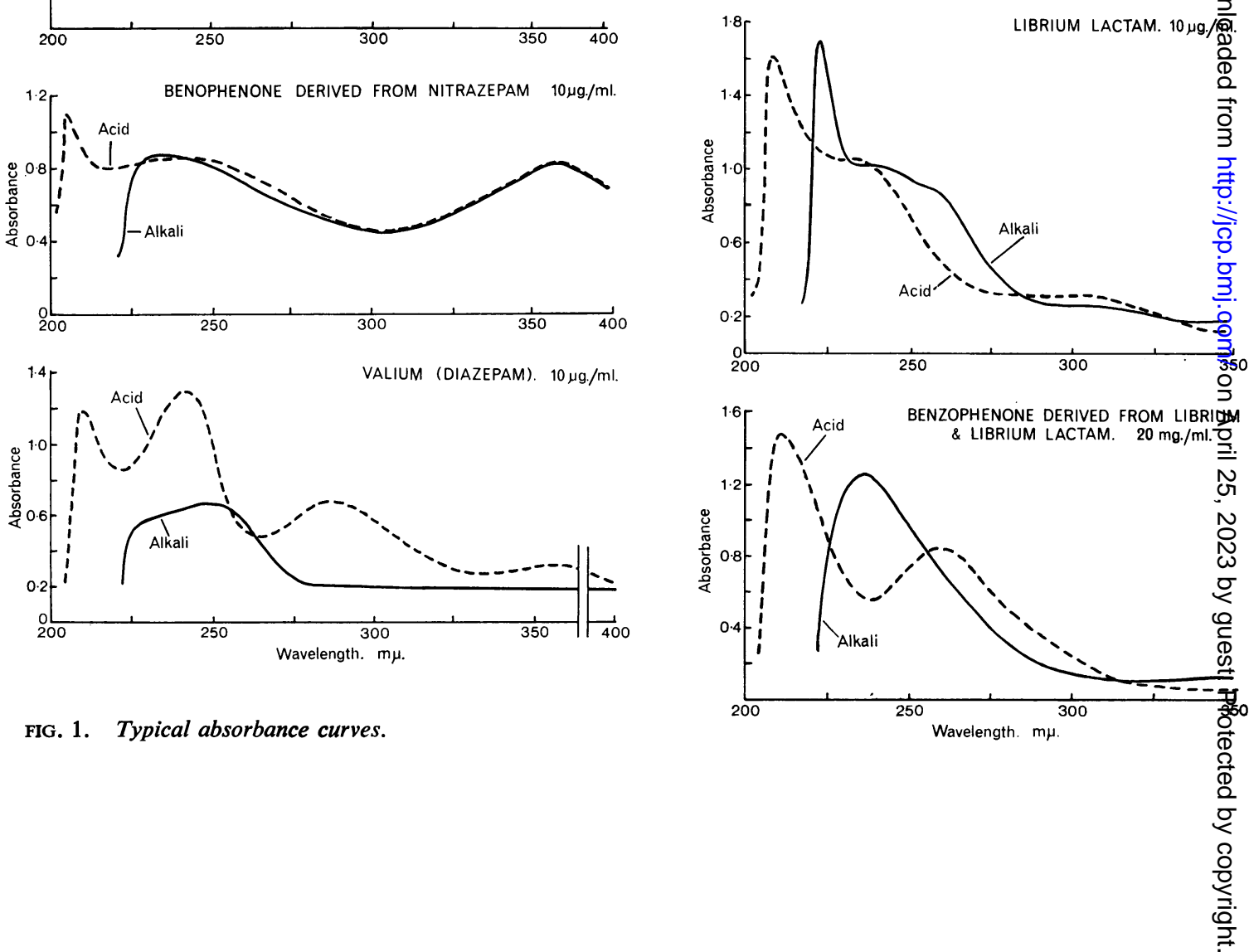

FIG. 1. Typical absorbance curves. 
$10 \mathrm{ml}$ of $\mathrm{N}$ hydrochloric acid are required. The final response to the Bratton and Marshall technique is linear, hence one standard, $e g, 50 \mu \mathrm{g}$, may suffice. Of the substance under examination, 25,50 , and $100 \mu \mathrm{g}$ in $2 \mathrm{ml}$ of $5 \mathrm{~N}$ hydrochloric acid and contained in $8 \times 1$ in. glass tubes fitted with glass stoppers are placed in a boiling water bath for one hour. The glass stoppers are not placed in position until the contents of the tubes have attained the temperature of the water bath. After cooling, the contents of the tubes are diluted to $10 \mathrm{ml}$ with water. The complete solvent procedure as described below for the blank and unknowns is applied before the application of the Bratton and Marshall technique.

The standards should be prepared at the same time as the unknowns.

REDUCED NITRAZEPAM PREPARED FOR USE Working standards containing benzophenone equivalent to 50 , 100 , and $200 \mu \mathrm{g}$ of unchanged nitrazepam in $10 \mathrm{ml}$ of $\mathrm{N}$ hydrochloric acid are required. The final response to the Bratton and Marshall technique is linear, hence one standard, $e g, 100 \mu \mathrm{g}$, may suffice.

Reduction To $1 \mathrm{mg}$ of nitrazepam contained in $10 \mathrm{ml}$ of water, added $60 \mathrm{mg}$ magnesium oxide. The mixture is shaken for 30 seconds, $0.5 \mathrm{~g}$ of sodium dithionite is added, the mixture shaken for 10 minutes and then placed in a water bath at $50^{\circ} \mathrm{C}$ for one hour. The mixture, after cooling, is acidified by the addition of ION hydrochloric acid and then diluted to $20 \mathrm{ml}$ with water. This mixture may be stored for future use.

Benzophenone formation Quantities equivalent to 50, 100 , and $200 \mu \mathrm{g}$ of the original unreduced nitrazepam contained in $2 \mathrm{ml}$ of $5 \mathrm{~N}$ hydrochloric acid are placed in $8 \times 1$ in. glass tubes fitted with glass stoppers and placed in a boiling water bath for one hour. The glass stoppers are not placed in position until the contents of the tubes have attained the temperature of the water bath. After cooling, the contents of the tubes are diluted to $10 \mathrm{ml}$ with water. The complete solvent procedure, as described below for the unknowns, is applied before the application of the Bratton and Marshall technique.

The standards should be prepared at the same time as the unknowns.

$\mathrm{N}$ hydrochloric acid, $10 \mathrm{ml}$, is used as a blank. preferably in an all-glass vacuum still, a water bath being used. The residue is dissolved in $10 \mathrm{ml} 5 \mathrm{~N}$ hydrochloric acid, and $2 \mathrm{ml}$ of this solution introduced into an $8 \times 1$ in. glass tube fitted with a glass stopper. The tube is placed in a boiling water bath for one hour, but the stopper is not placed in position until the tube has attained the temperature of the water bath. At the end of this period, both initially unchanged and reduced nitrazepam are converted into their respective benzophenones.

(a) Nitrazepam benzophenone The cooled mixture is diluted to $10 \mathrm{ml}$ with water and $40 \mathrm{ml}$ of $\mathrm{n}$-heptane added. The mixture is shaken vigorously for two minutes. After allowing the mixture to settle, $35 \mathrm{ml}$ of the heptane extract is transferred to a flask (suitable for attachment to an all-glass vacuum still) containing 4 drops of $10 \mathrm{~N}$ hydrochloric acid. The solvent is then removed by evaporation using an all-glass vacuum still, and heated in a water bath which is initially at room temperature.

(b) Reduced nitrazepam benzophenone The aqueous, residue from $(a)$ is used. The remaining heptane is removed and rejected. The aqueous residue is then extracted twice with $5 \mathrm{ml}$ quantities of heptane, the extracts being rejected. Solid sodium hydrogen carbonate is added until the reaction is neutral, after which $40 \mathrm{ml}$ of chloroform is added. The mixture is shaken vigorously for two minutes. The aqueous layer is removed and rejected. Anhydrous sodium sulphate is added to effect dehydration. The chloroform extract is filtered, $30 \mathrm{ml}$ evaporated to dryness under the conditions described in $(a)$.

To the residues obtained in $(a)$ and $(b)$ is added $10 \mathrm{ml}$ $\mathrm{N}$ hydrochloric acid and the determinations are completed using the Bratton and Marshall reaction.

(c) The Bratton and Marshall reaction To blank, standards, and unknowns is added $1 \mathrm{ml}$ of $0.1 \%$ sodium nitrite followed five minutes later by $1 \mathrm{ml}$ of $0.5 \%$ ammonium sulphamate. At this stage it is essential to ensure complete mixing since traces of nitrous acid will react with the coupling reagent to produce a purple colour. Five minutes after the addition of sulphamate, $1 \mathrm{ml}$ of the coupling reagent is added, and 15 minutes later absorbances are read at $560 \mathrm{~m} \mu$.

\section{BLOOD SERUM}

PROCEDURE Urine, $50 \mathrm{ml}$, is evaporated to dryness, Blood serum is treated with acetone according to the

TABLE

\begin{tabular}{|c|c|c|c|c|c|c|c|}
\hline \multirow[t]{2}{*}{ Case No. } & \multicolumn{2}{|l|}{$\begin{array}{l}\text { In Blood Serum } \\
(\mu g / 100 \mathrm{ml})\end{array}$} & \multirow[t]{2}{*}{$\begin{array}{c}\text { FOR NITRAZEPAM } \\
\text { Urine Volume }(\mathrm{ml})\end{array}$} & \multicolumn{2}{|c|}{$\begin{array}{l}\text { AND LIBRIUM IN BLOOD } \\
\text { In Urine } \\
(\mu \mathrm{g} / 100 \mathrm{ml})\end{array}$} & \multirow[t]{2}{*}{$\begin{array}{l}\text { AND URINE } \\
\text { Volume }(\mathrm{ml})\end{array}$} & \multirow[t]{2}{*}{$\begin{array}{l}\text { Librium in Urine } \\
(\mu \mathrm{g} / 100 \mathrm{ml})\end{array}$} \\
\hline & Unchanged & Reduced & & Unchanged & Reduced & & \\
\hline $\begin{array}{l}1 \\
2 \\
3 \\
4 \\
5 \\
6 \\
7 \\
8 \\
9 \\
10 \\
{ }^{1} \text { Eight hou }\end{array}$ & $\begin{array}{l}10 \\
\text { Not detectable } \\
700 \\
33 \\
70 \\
42 \\
60 \\
300 \\
85\end{array}$ & $\begin{array}{r}1105 \\
170 \\
1,200 \\
450 \\
225 \\
310 \\
110 \\
850 \\
730\end{array}$ & $\begin{array}{r}520 \\
780 \\
1,000 \\
1,250 \\
1,100 \\
870 \\
1,020 \\
340 \\
320 \\
660\end{array}$ & $\begin{array}{r}110 \\
85 \\
80 \\
86 \\
33 \\
70 \\
40 \\
\text { nil } \\
60 \\
60\end{array}$ & $\begin{array}{r}900 \\
620 \\
250 \\
2,500 \\
450 \\
225 \\
1,000 \\
340 \\
210 \\
580\end{array}$ & $\begin{array}{r}80 \\
320 \\
680 \\
240 \\
140 \\
260 \\
1,050 \\
700 \\
760 \\
1,550 \\
580\end{array}$ & $\begin{array}{r}2,400 \\
1,030 \\
275 \\
640 \\
855 \\
200 \\
50 \\
240 \\
870 \\
130 \\
1,360\end{array}$ \\
\hline
\end{tabular}


procedure of Moss (1954). The acetone extract from five $\mathrm{ml}$ serum is evaporated to dryness and the residue treated with $2 \mathrm{ml} 5 \mathrm{~N}$ hydrochloric acid in a boiling water bath as described above. After adding $\mathbf{N}$ hydrochloric acid to the residue from the heptane extract, turbidity from fat, etc, is frequently encountered, but it can usually be removed by filtration through a Whatman no. 42 filter paper.

\section{DETERMINATION OF LIBRIUM IN URINE}

The procedure is exactly the same as that described for the determination of unchanged nitrazepam in urine except that the benzophenone derived from librium is used as a standard.

\section{RESULTS}

Results obtained from cases suspected of nitrazepam overdosage are shown in the Table, and of urine analysis from cases suspected of librium overdosage are also shown. The writer prefers to use the spectrofluorimetric method of Koechlin and d'Arconte (1963) for the determination of librium in serum (Tompsett, 1967).

\section{DISCUSSION}

Frequently in hospital practice the nature of the drug involved is known but there are occasions when the identity of the drug is not known, and then the specificity of a method assumes some importance.

When applied to normal serum and blood, the above procedures record zero values. The use of heptane extraction at an acid reaction limits reactant substances to the benzophenones of librium and unchanged nitrazepam. When chloroform is used as the solvent substances other than the benzophenones of librium and unchanged nitrazepam also reacting in the Bratton and Marshall technique will be included, and they appear to be aminobenzoic acids. After ingestion of librium and valium, Bratton and Marshall reactant substances will only be encountered in the unchanged nitrazepam fraction, none being found in the reduced nitrazepam fraction. After the Bratton and Marshall technique has been applied to the unchanged and reduced nitrazepam fractions, there is an obvious distinction in the tints of the colours produced. Neutrality was selected in preference to an alkaline reaction for the separation of the reduced nitrazepam fraction to reduce losses as the result of oxidation as the substance is a paradiamino compound. The benzophenone of reduced nitrazepam may be extracted from aqueous solutions by heptane but recoveries are larger when chloroform is used. Interference from other drugs is most likely at this stage of the procedure.
Certain of the sulphonamide drugs with a reactive amino group are extracted from aqueous $\frac{}{-}$ neutral solutions by chloroform but not by heptane. Phenylbutazone (butazolidin) is converted into a 5 diazotizable amine, benzidine (Moss, 1954) under the conditions used for the production of the benzophenones of librium and nitrazepam. This amine produces a distinctive colour when the $\stackrel{\varnothing}{\circ}$ Bratton and Marshall technique is applied and $\cong$ would be recoverable in the reduced nitrazepam fraction. The presence of phenylbutazone may be detected by an independent procedure (Burns, Rose, Chenkin, Goldman, Schulert, and Brodie, 1953). The drug tanderil, which is also a metabolite of 8 phenylbutazone, forms a diazotizable amine under $i$ these circumstances but is not extractable by $\vec{\omega}$ organic solvent (Tompsett, 1963)

When 'librium' is detected in urine, the question can arise as to whether the source is ingested librium, valium, or even both. The obvious approach to this problem is the use of gas-liquid chromatography using the electron capture technique, if this is available (de Silva et al., 1966). Another $\overrightarrow{0}$ method which is not quite as satisfactory is the spectrofluorimetric examination of blood serum (Koechlin and d'Arconte, 1963; Tompsett, 1967). When librium has been swallowed blood serum can be shown to contain unchanged librium and possibly some lactam whereas after valium only librium lactam can be detected.

The examination of biological material to determine whether or not a drug has been ingested has always proved to be a problem. The difficulty is to ensure that all the tests used are adequate and that nothing has been missed. The objective may be to ensure that a drug has not been ingested or that following the identification of one drug that others are not involved. Of the materials available for initial examination, the urine collected after the patient's admission proves to be the most suitable. Ultraviolet spectrophotometry, using a recording instrument and a preliminary separation by organic solvent or by distillation in the presence of sodium bicarbonate (Goldbaum and Domanski, 1965), has $N$ proved extremely useful since a very wide range of $N$ basic drugs, eg. the phenothiazines or the ampheta- N mines, etc., can be covered. Unfortunately this technique does not cover all the possible organic substances, eg, nitrazepam, librium, phenacetin, panadol, etc. As a result, the technique described $\stackrel{\oplus}{\rightarrow}$ in this paper is now included in screening proce- 0 dures. Using the residues obtained for the detection of the benzophenone derived from reduced nitrazepam, p-aminophenol, derived from phenacetin and panadol, may be detected if present (Tompsett, 1958, 1966). Chloroform has proved to be a better 
solvent for p-aminophenol extraction than ether as used originally, as ether contains substances which produce a blank value when the reaction is applied.

\section{REFERENCES}

Bäumler, J., and Rippenstein, S. (1961). Helv. chim. Acta, 44, 2208. Bratton, A. C., and Marshall, E. K. (1939). J. Biol. Chem., 128, 537.

Burns, J. J., Rose, R. K., Chenkin, T., Goldman, A., Schulert, A., and Brodie, B. B. (1953). J. Pharmacol. exp. Ther., 109, 346.
Goldbaum, L. R., and Domanski, T. J. (1965). Progr. chem. Toxicol., $2,221$.

Koechlin, B. A., and d'Arconte, L. (1963). Analyt. Biochem., 5, 195. Moss, D. G. (1954) J. clin. Path., 7, 344.

Randall, L. O. (1961). Dis. Nerv. Syst., 22, July suppl. 7, 1.

Rieder, J. (1965). Artzneimittel-Forsch., 15, 1134.

de Silva, J. A. F., Koechlin, B. A., and Bader, G. (1966). J. pharm. Sci., 55, 692 .

Tompsett, S. L. (1958). Clin. chim. Acta, 3. 149.

(1960). Ibid., 5, 415.

(1963). Unpublished.

(1966). Bull. int. Ass. forens. Toxicol., 3, (4), 1.

(1967). Proc. Ass. clin. Biochem., 4, 164. 